\title{
Diversidade polínica das Mimosoideae (Leguminosae) ocorrentes em uma área de caatinga, Pernambuco, Brasil ${ }^{1}$
}

\author{
Maria Teresa Buril ${ }^{2,4}$, Francisco de Assis Ribeiro do Santos² e Marccus Alves ${ }^{3}$
}

Recebido em 19/12/2008. Aceito em 1/04/2009

RESUMO - (Diversidade polínica das Mimosoideae (Leguminosae) ocorrentes em uma área de caatinga, Pernambuco, Brasil). O município de Mirandiba, Pernambuco, considerado prioritário para a conservação da caatinga, apresenta cerca de $25 \%$ das espécies de Leguminosae do bioma, sendo 23 espécies em 13 gêneros da subfamília Mimosoideae, das quais 6 espécies são endêmicas. Dezenove táxons desta subfamília tiveram seus grãos de pólen caracterizados por microscopia óptica e eletrônica de varredura, ilustrados e incluídos em uma chave de identificação. A morfologia polínica dos táxons estudados é muito variada, principalmente em relação às unidades de dispersão, sendo encontradas desde mônades, em Neptunia e Desmanthus; políades com oito grãos de pólen, uniplanar em Calliandra depauperata e multiplanar em Mimosa spp. e Pityrocarpa moniliformis, políades com 16 grãos de pólen, em Anadenanthera, Inga, Parapiptadenia, Pithecellobium e Senegalia, tétrades também em espécies de Mimosa, e políades amorfas com 32 grãos de pólen, presentes em Chloroleucon e Pithecellobium. Essas diferenças aliadas a caracteres morfométricos e da ectexina possibilitam a identificação da maioria dos táxons de Mimosoideae de Mirandiba.

Palavras-chave: Leguminosae, Mimosoideae, caatinga, políade, tétrade

\begin{abstract}
Pollen diversity of Mimosoideae taxa (Leguminosae) from a caatinga region, Pernambuco, Brazil). Mirandiba municipality in Pernambuco, is a prioritary conservation area for caatinga. It has almost $25 \%$ of Leguminosae species from the caatinga, where 23 species in 13 genera belong to the Mimosoideae subfamily and 6 species are endemics. The pollen grains of 19 mimosoid taxa were characterized by their pollen grains using light and scanning electron microscopy. All taxa are illustrated and keyed. Pollen morphology of these taxa is varied, mainly regarding pollen units; we found monads in Neptunia and Desmanthus; 8-grain uniplanar polyads in Calliandra depauperata and multiplanar ones in Mimosa spp. and Pityrocarpa moniliformis, tetrads also in Mimosa, polyads with 16 pollen grains in Anadenanthera, Inga, Parapiptadenia, Pithecellobium and Senegalia, and polyads with 32 pollen grains in Chloroleucon and Pithecellobium. Different pollen units allied to other morphometric and ectexine characters were useful to identify most mimosoid taxa from Mirandiba.
\end{abstract}

Key words: Leguminosae, Mimosoideae, caatinga, polyad, tetrad

\section{Introdução}

Leguminosae, família que abrange no Brasil cerca de 200 gêneros e 1.500 espécies presentes nos mais variados ecossistemas (Souza \& Lorenzi 2005), desponta como uma das famílias mais representativas do bioma caatinga inclusive com o maior número de espécies endêmicas (Giullieti et al. 2002). Esse bioma, apesar de cada vez mais ser apontado como hot-spot de diversidade, com a presença de vários táxons endêmicos, é ainda a região cuja fauna e flora são as menos conhecidas da América do Sul (Sampaio et al. 2002). Em relação aos estudos de sua flora, ainda mais escassos são os estudos palinológicos, que além de serem relevantes para o conhecimento da biodiversidade local, podem subsidiar pesquisas melissopalinológicas, de ecologia da polinização e paleobotânicas (Melhem et al. 2003).

A delimitação taxonômica de Leguminosae é um tema bastante discutido e alguns autores como Lewis (1987), Judd et al. (1999), Smith et al. (2004) e Simpson (2006), admitem três subfamílias: Caesalpinioideae, Papilionoideae (Faboideae) e Mimosoideae, que podem ser distintas principalmente pela morfologia floral. Palinologicamente, as leguminosas apresentam uma grande diversidade de caracteres, sendo amplamente aceita como uma família euripolínica. É caracterizada por ter grãos de pólen em mônades, tricolpados e tectado-reticulados, sendo este um padrão geral para as angiospermas mais derivadas (Guinet 1981). A diversidade palinológica permite delimitação de tribos, subtribos e até gêneros, entretanto, a família apresenta poucas variações interespecíficas (Vishnu-Mitre \& Sharma 1962).

Mimosoideae, ao contrário das outras subfamílias, destaca-se por apresentar políades como principal tipo de unidade de dispersão, sendo comum a heterogeneidade no tamanho dos grãos de pólen, no tipo apertural que pode ser porado ou colporado, e nos padrões de ornamentação (Guinet 1981).

Pioneiramente, Kunth (1819) mencionou a presença de políades no gênero Acacia, e estudos conseguintes trataram de descrições detalhadas desse tipo de unidade em outros gêneros e espécies, como no trabalho de Von Mohl (1835). Rosanoff (1865) ressaltou a importância dos caracteres polínicos para a taxonomia das Mimosoideae, separando os gêneros em três grupos: aqueles com mônades, os com tétrades e os com políades compostas por oito, 12, 16 ou 32 grãos de pólen. Outra classificação foi sugerida por Van Campo \& Guinet (1961) que, ao estudarem detalhadamente a morfologia polínica das Mimosoideae, além de enfatizarem a heterogeneidade entre os tipos de unidades de dispersão, ainda distinguiram as tétrades e as políades de acordo com a estratificação da exina, podendo ser calimadas, com uma camada da exina envolvendo toda a unidade, ou acalimadas, onde cada grão de pólen tem uma parede individualizada.

\footnotetext{
1 Parte da Dissertação de Mestrado da primeira Autora

2 Universidade Estadual de Feira de Santana, Departamento de Ciências Biológicas, Feira de Santana, BA, Brasil

3 Universidade Federal de Pernambuco, Departamento de Botânica, Recife, PE, Brasil

4 Autor para correspondência: teresavital@gmail.com
} 
Além disso, Van Campo \& Guinet (1961) citaram que as formas não compostas podem ser eumônades, mônades ou pseudo-tétrades. Sorsa (1969) organizou a subfamília em cinco grupos de acordo com a morfologia polínica, citando como menos derivado aquele com mônades tricolpadas e corroborou a heterogeneidade palinológica de valor taxonômico importante para distinguir tribos e até mesmo gêneros.

Assim, o trabalho tem como objetivo investigar a diversidade que as espécies de Mimosoideae (Leguminosae) da caatinga do município de Mirandiba (Pernambuco) apresentam em suas unidades polínicas, subsidiando pesquisas de melissopalinologia e de ecologia da polinização, além de fornecer informações úteis para a taxonomia do grupo.

\section{Material e métodos}

Área de estudo - O município de Mirandiba situa-se na Mesorregião de Sertão de Pernambuco, a cerca de $500 \mathrm{~km}$ da capital Recife, na microrregião de Salgueiro, fronteira norte da Depressão Sertaneja meridional. Compreende uma área de $809 \mathrm{~km}^{2}$, coordenada central $08^{\circ} 13^{\prime}$ 'S e $38^{\circ} 43^{\prime} \mathrm{W}$, altitude variando entre 300-500 m. O clima da região é BShw' segundo Köppen, com chuvas concentradas de janeiro a junho e precipitação média anual de $611 \mathrm{~mm}$, com estação seca prolongada e com taxas de evaporação elevadas chegando até $2000 \mathrm{~mm} / \mathrm{ano}$. Na região são observadas áreas de formação cristalina e sedimentar (Sampaio 1995).

A vegetação da área é uma caatinga hiper e hipoxerófila formando um mosaico de fisionomias, desde campos abertos até caatinga arbórea. Apesar de inicialmente ter sido tratada como área em estado avançado de degradação como as cidades circunvizinhas (Córdula et al. 2008), Mirandiba mostrou-se em ótimo estado de preservação. É considerada pelo Ministério do Meio Ambiente (2002) como área prioritária para conservação da caatinga e isenta de investigações científicas, chamando a atenção para a tomada de medidas urgentes de preservação.

Segundo o levantamento de Córdula et al. (2008), as Leguminosae estão representadas na flora de Mirandiba por 81 espécies, as quais constituem $25 \%$ das espécies desta família citadas para a caatinga (Queiroz 2006). Nessa lista florística, as Mimosoideae estão presentes com 23 táxons em 13 gêneros, sendo seis consideradas endêmicas da caatinga (Queiroz 2006).

Os táxons Senegalia recurva (Benth.) Seigler \& Ebinger, frequentemente designada como Senegalia riparia (Kunth) Britton \& Rose ex Britton \& Killip, Senegalia polyphylla (DC.) Britton \& Rose, Piptadenia viridiflora (Kunth.) Benth. e Mimosa modesta var. ursinoides (Harms) Barneby apesar de ocorrerem na área, não foram inclusas nas análises palinológicas pois não foi obtido de material fértil na área de estudo.

Análises palinológicas - O material polínico analisado foi obtido a partir de botões de espécimes coletados na área de estudo e depositadas no Herbário UFP e os materiais adicionais foram coletados de exsicatas depositadas nos herbários UFP, IPA e HUEFS (acrônimos conforme Holmgren \& Holmgren 2006). Para cada espécie (Tab. 1), sempre que possível foram estudadas três populações diferentes.

Para análise em microscopia óptica (MO), o material polínico foi preparado pelo método padrão de acetólise (Erdtman 1960), com adaptação apenas para redução do número de rotações para 2.100 rpm, a fim de diminuir a dissociação das políades. Para a microscopia eletrônica de varredura (MEV), as anteras herborizadas foram diretamente depositadas sobre stubs para metalização. Em MO, os diâmetros das unidades polínicas foram medidos em 25 unidades (grãos de pólen, tétrades ou políades) aleatoriamente, com algumas exceções em decorrência do número de grãos de pólen ser insuficiente. As medidas de exina (nexina e sexina) foram realizadas em dez unidades polínicas aleatórias.

As descrições foram realizadas de acordo com a nomenclatura proposta por Punt et al. (2007) e as lâminas depositadas na Palinoteca do Laboratório de Micromorfologia Vegetal (LAMIV), da Universidade Estadual de Feira de Santana.

\section{Resultados}

Os táxons de Mimosoideae (Leguminosae) ocorrentes em Mirandiba têm uma variabilidade de unidades de dispersão que possibilitou o reconhecimento de sete tipos polínicos. Foram encontrados desde mônades, em Desmanthus pernambucanus (L.) Thell. e Neptunia plena (L.) Benth.; tétrades em espécies de Mimosa L.; políades com oito grãos de pólen heteromórficos (um grão de pólen muito diferenciado dos demais) em Calliandra depauperata Benth.; ditétrades em espécies de Mimosa e Pityrocarpa moniliformis (Benth.) Luckow \& R.W.Jobson.; políades com 12 grãos de pólen em Piptadenia Benth.; políades com 16 grãos de pólen nas espécies de Anadenanthera Speg., Inga Mill., Parapiptadenia Brenan., Pithecellobium Mart. e Senegalia Raf. e políades com mais de 16 grãos de pólen em Chloroleucon Britton \& Rose e Pithecellobium Mart. Dentre cada tipo, as diferenças intra-específicas estão geralmente relacionadas à estrutura da exina, espessura das camadas e aos elementos de ornamentação.

Tipo 1 - caracterizado pelos grãos de pólen em mônades.

Espécies incluídas: Desmanthus pernambucanus e Nep-

tunia plena (Fig. 1-12).

Essas espécies têm grãos de pólen médios (a grandes em N. plena), isopolares, âmbito circular a subcircular, suboblatos a oblato-esferoidais; 3-colporados (às vezes 4-colporados em $N$. plena), endoabertura circular com costa (Fig. 3, 7, 9-10), membrana apertural granulada; exina estriada (Fig. 4-6, 10, 12). A superfície dos grãos de pólen quando observada sob MO pode ser definida como estriado-reticulada.

Tipo 2 - políades uniplanares, plano-elípticas, em forma

de gota e com oito grãos de pólen. Espécie incluída:

Calliandra depauperata (Fig. 13-18).

Políades muito grandes compostas por oito grãos de pólen, calimadas, ovais, assimétricas, um grão de pólen apical elíptico, sem apêndice e com um poro na extremidade. Os grãos de pólen centrais têm seus 4-5 poros nos pontos de contatos com outros 2-3 grãos de pólen (Fig. 16). A exina tem ca. $7 \mu \mathrm{m}$ de espessura, sendo a sexina mais espessa que a nexina, com superfície irregularmente rugulada (Fig. 18); contudo sob MO aparece microrreticulada.

Tipo 3 - políades plano-circulares, com oito grãos centrais

(quatro em cada plano) margeados por uma crista circular composta pelos demais oito grãos de pólen é o principal caráter distintivo deste tipo. Táxons incluídos: Anadenanthera colubrina (Vell.) Brenan var. colubrina, Inga vera Willd., Parapiptadenia zehntneri (Harms) M.P.M. de Lima \& H.C. de Lima, Pithecelobium diversifolium Benth. e Senegalia piauhiensis (Benth.) Seigler \& Ebinger (Fig. 19-30).

As políades são de tamanho médio, grande apenas em $P$. diversifolium. Há de 4-6 poros em cada grão de pólen, situados sempre na parede de contato com outros grãos de pólen. A exina em A. colubrina var. colubrina e P. zehntneri 
é areolada (Fig. 19, 25); em I. vera, P. diversifolium e em $S$. piauhiensis é psilada (Fig. 22-23, 27-30); Em P. diversifolium e $S$. piauhiensis são ainda visualizadas depressões na região distal de cada grão de pólen (Fig. 27, 30). Apenas em $A$. colubrina e $I$. vera a sexina é mais espessa que a nexina, nas demais espécies as camadas são iguais em espessura (Tab. 1). Tipo 4 - políades multiplanares, constituídas por oito grãos de pólen. Espécies incluídas: Mimosa arenosa (Willd)
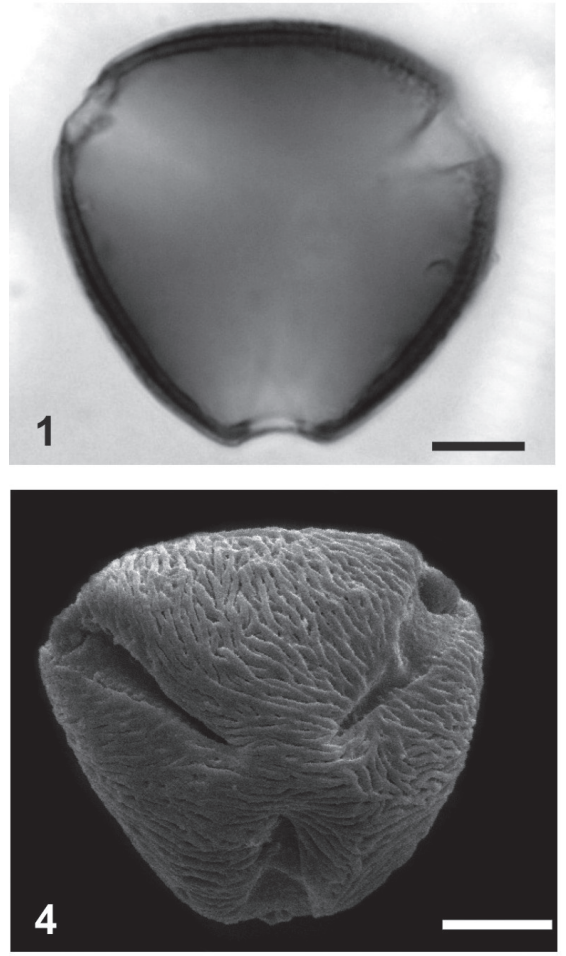$$
2
$$
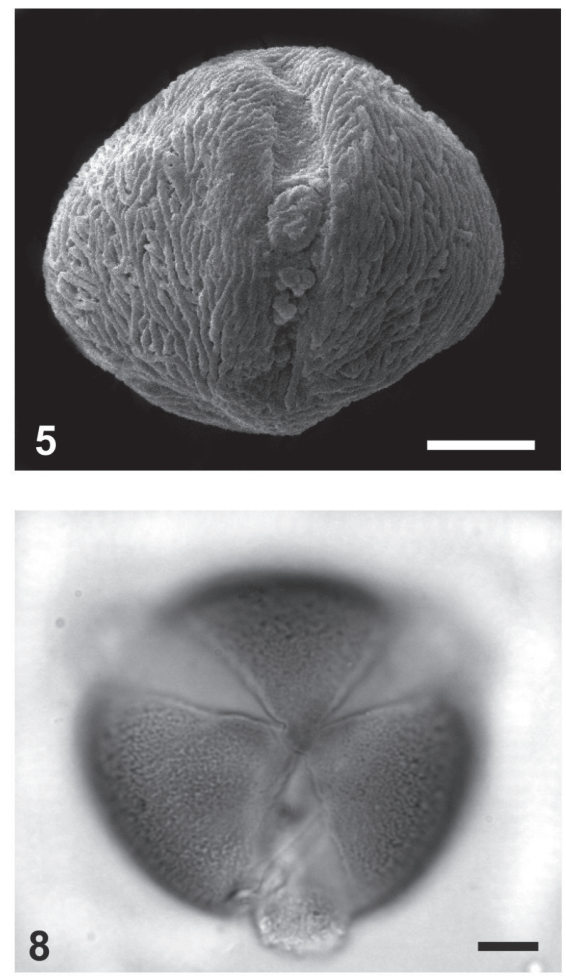

\section{7}
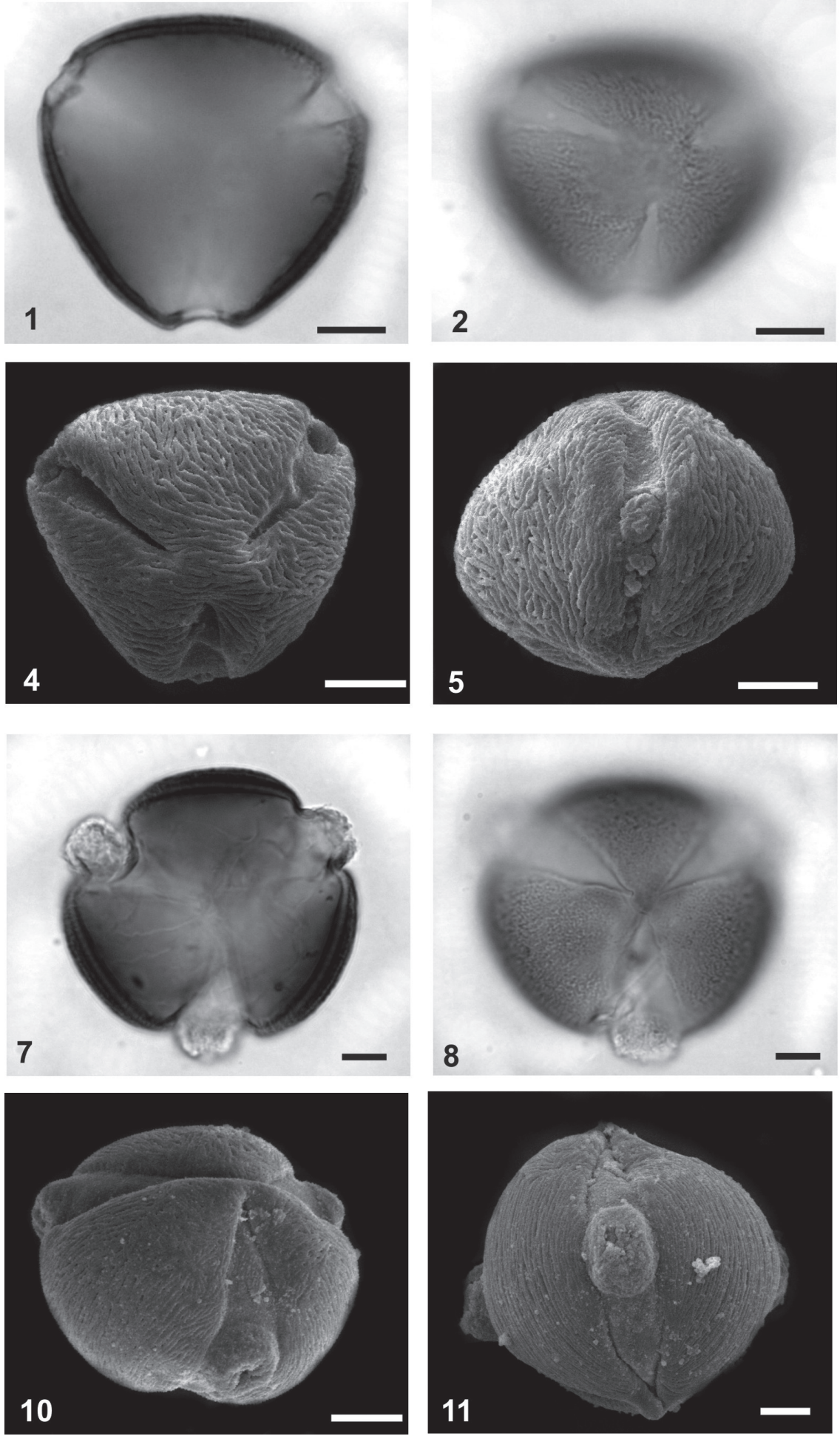

3
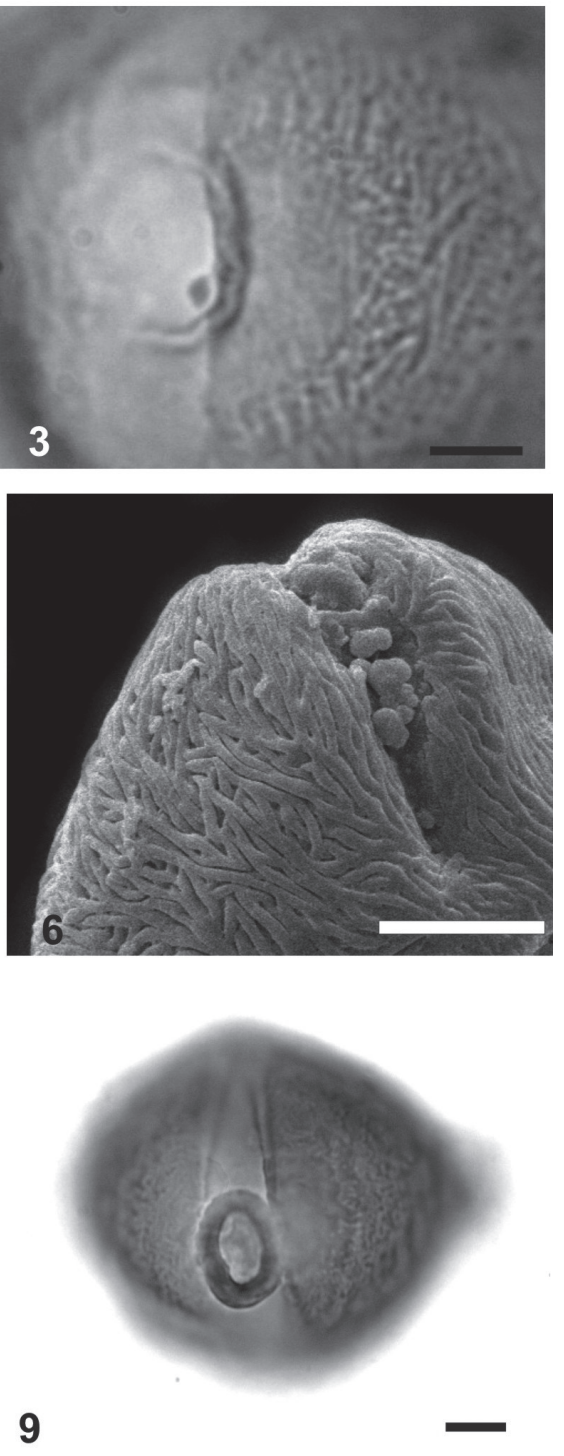

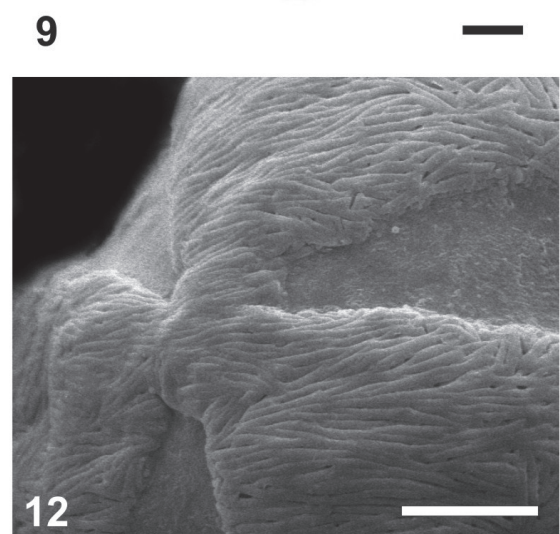

Figuras 1-12. Grãos de pólen de Leguminosae Mimosoideae de Mirandiba, Pernambuco, Brasil. - Tipo 1. 1-6 Desmanthus pernambucanus, 1 - vista polar, corte óptico (MO), 2 - vista polar, superfície (MO), 3 - vista equatorial, detalhe da abertura (MO), 4 - vista polar (MEV), 5 - vista equatorial (MEV), 6 - detalhe da exina (MEV); 7-12 Neptunia plena, 7 - vista polar, corte óptico (MO), 8 - vista polar, superfície (MO), 9 - vista equatorial (MO), 10 - vista polar (MEV), 11 - vista equatorial (MEV), 12 - detalhe da exina (MEV). Escalas: $10 \mu \mathrm{m}$. 

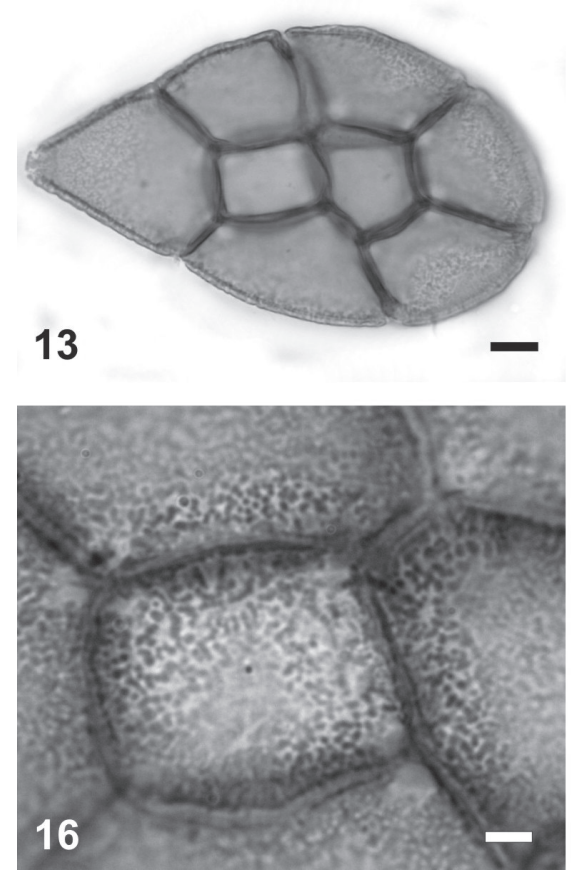
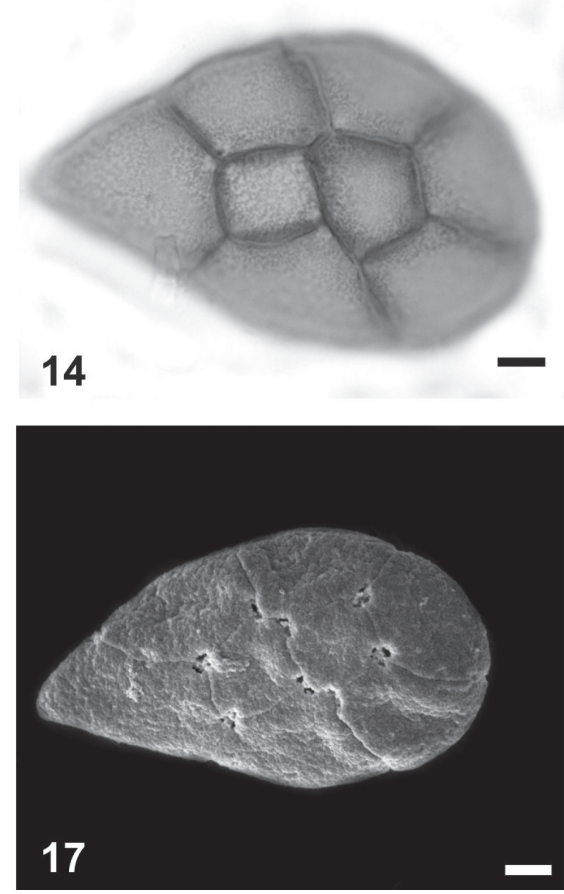
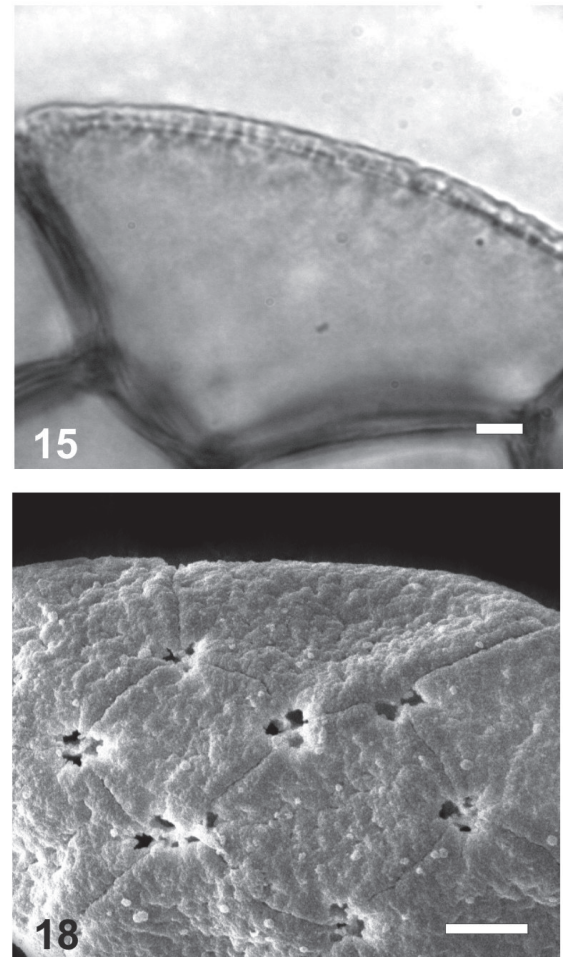

Figuras 13-18. Grãos de pólen de Leguminosae as Mimosoideae de Mirandiba, Pernambuco, Brasil. - Tipo 2. Calliandra depauperata, 13 - vista geral, corte óptico (MO), 14 - vista geral, superfície (MO), 15 - corte óptico, detalhe da exina (MO), 16 - detalhe de um grão central, com poros (MO), 17 - vista geral (MEV), 18 detalhe da superfície (MEV). Escalas: $10 \mu \mathrm{m}$.

Poir, Mimosa ophtalmocentra Mart. ex Benth, Pityrocarpa moniliformis (Fig. 31-39).

Esse tipo polínico pode ser subdividido em dois subtipos: 4a, no qual as políades são constituídas por duas tétrades tetragonais unidas, ocorrem em M. arenosa (Fig. 31) e M. ophtalmocentra (Fig. 36), e o 4b com políades com seis grãos de pólen periféricos e dois centrais, presentes em P. moniliformis (Fig. 37-39). Ambos os tipos de políades são de tamanho pequeno, acalimadas, com grãos de pólen (3)4(5)-porados; exina muito delgada com camadas não diferenciadas. A superfície da exina das póliades de $P$. moniliformis se destaca por apresentar uma região mais elevada contornando a face externa de cada grão de pólen (Fig. 39).

Tipo 5 - doze grãos de pólen constituem a políade deste tipo. Espécie incluída: Piptadenia stipulacea (Benth.) Ducke (Fig. 40-42).

São políades de tamanho pequeno, acalimadas, com grãos de pólen organizados em seis periféricos e seis $(3+3)$ centrais, com forma variável de esférica a elíptica (Fig. 40); cada grão é (3)4-porados, poros recobertos por membrana finamente granulada, exina, psilada sob $\mathrm{MO}$, é na verdade areolada, com aréolas irregularmente fusionadas (Fig. 42).

Tipo 6 - grãos de pólen dispersos em tétrades. Táxons incluídos: Mimosa invisa Mart. ex Colla., Mimosa quadrivalvis var. leptocarpa (DC). Barneby, Mimosa sensitiva L. e Mimosa tenuiflora (Willd.) Poir. (Fig. 43-54).
Esse tipo também pode ser dividido em dois subtipos: 6a, tétrades tetraédricas esféricas e $6 \mathrm{~b}$, tétrades plano-elipticas ou plano-ovais. No primeiro subtipo estão as tétrades tetraédricas muito pequenas de Mimosa sensitiva L. (Fig. 49-51), e no segundo as tétrades das demais espécies: decussadas romboidais pequenas em Mimosa tenuiflora (Willd.) Poir. (Fig. 52-54) e romboidais ou tetragonais pequenas em Mimosa invisa Mart. ex Colla. (Fig. 43-45) e médias em Mimosa quadrivalvis var. leptocarpa (L.) DC. Barneby (Fig. 46-48). Os grãos de pólen são 4-porados, exina muito delgada $(<1 \mu \mathrm{m})$ com camadas não diferenciadas. A superfície é irregularmente areolada, contudo em M. tenuiflora parece ser escabrada (Fig. 54).

Tipo 7 - políades plano-circulares (ou menos frequentemente plano-elípticas) com 32 grãos de pólen, geralmente organizados em 16 centrais e 16 periféricos, ou irregularmente distribuídos. Espécies incluídas: Chloroleucon dumosum (Benth.) G.P. Lewis, Chloroleucon foliolosum (Benth.) G.P. Lewis e Enterolobium contortisiliqum (Vell.) Morong. (Fig. 55-60).

As políades são grandes, calimadas, elípticas, exina psilada (Fig. 56, 58, 80) Os grãos de pólen são angulaperturados, 4-5 porados (Fig. 57), com poros de contorno irregular e recobertos por membrana granular. As políades de $C$. foliolosum são ligeiramente maiores que as de $C$. dumosum (Tab. 1). Nas espécies deste tipo polínico, são observadas depressões irregulares na superfície distal dos grãos de pólen. 

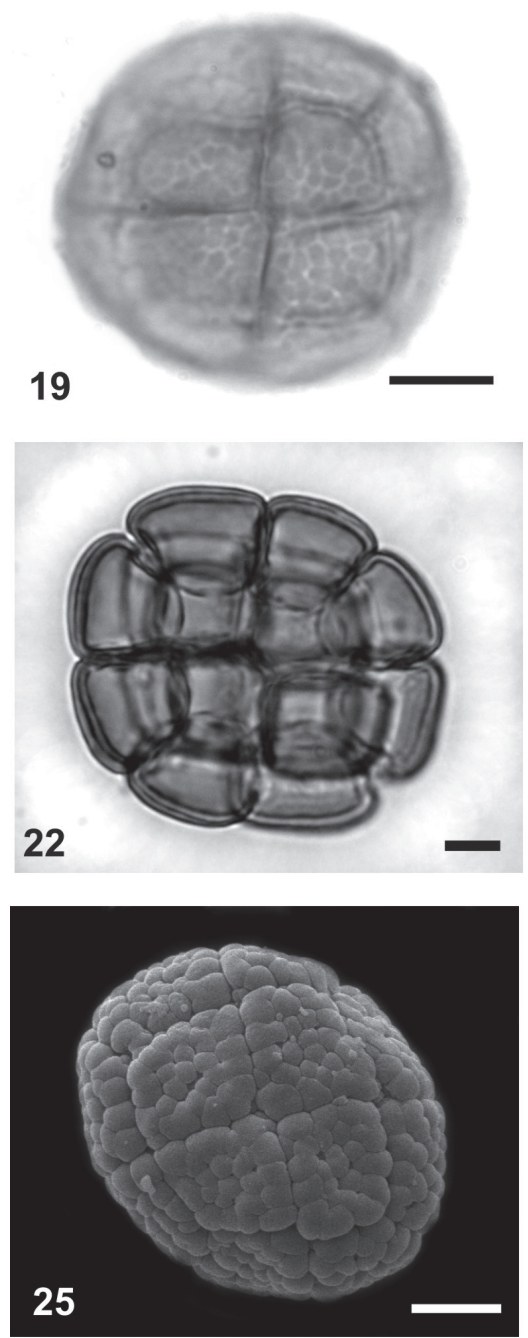

28

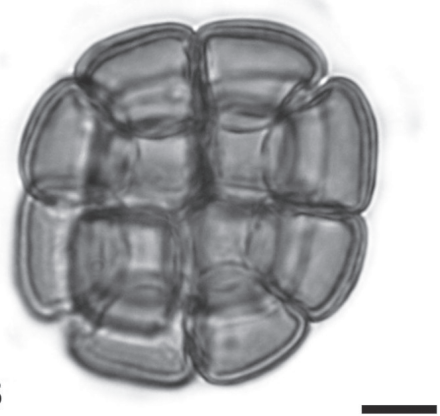

20

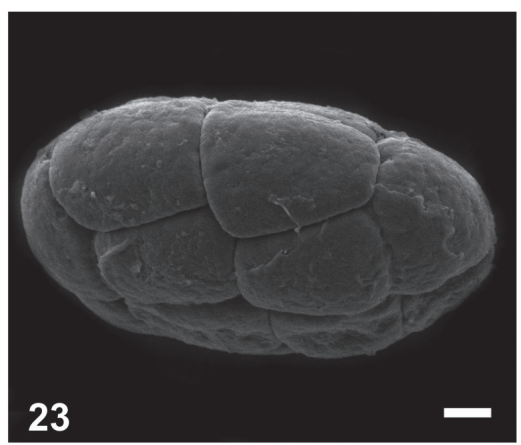

26
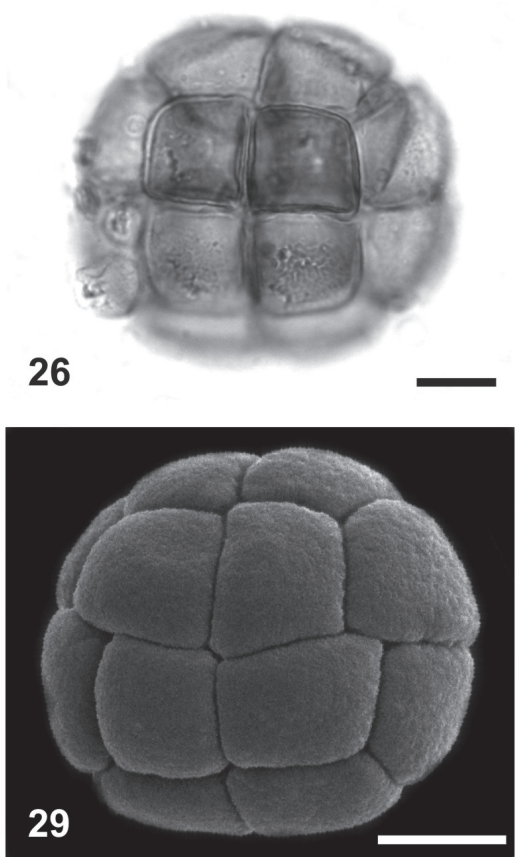

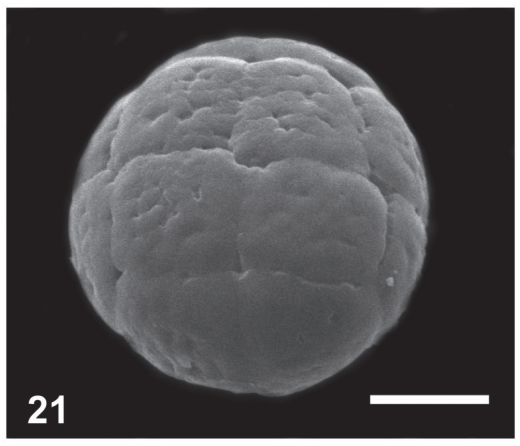

24
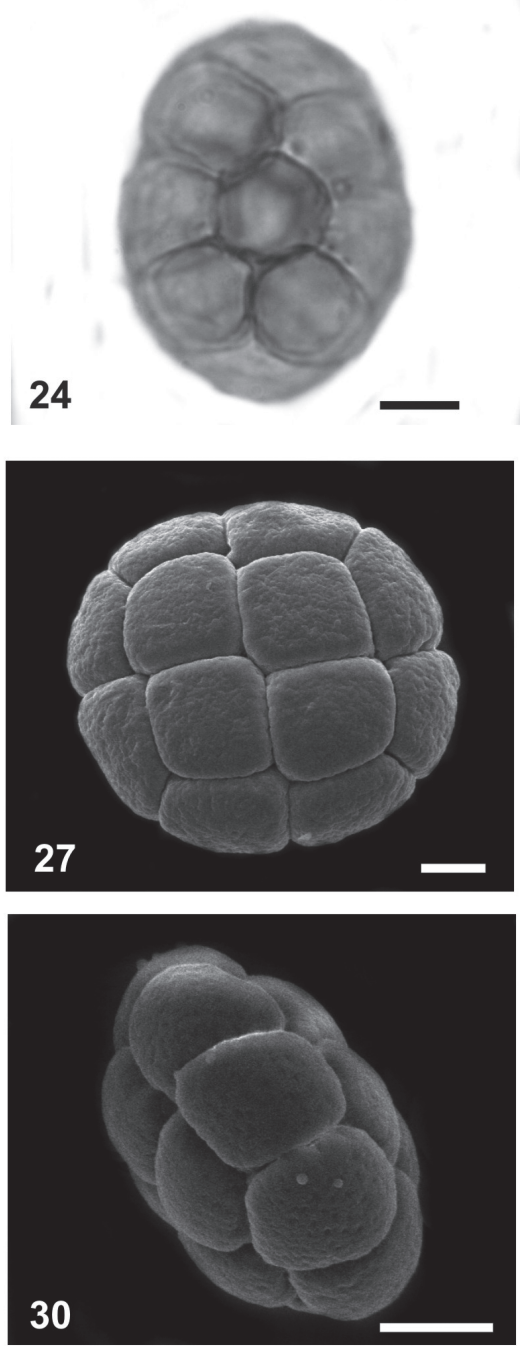

Figuras 19-30. Grãos de pólen de Leguminosae Mimosoideae de Mirandiba, Pernambuco, Brasil. - Tipo 3. 19-21 Anadenanthera colubrina var. colubrina, 19 - vista frontal, superfície (MO), 20 - vista lateral, corte óptico (MO), 21 - vista frontal (MEV); $22-23$ Inga vera, 22 - vista frontal, corte óptico (MO), 23 - vista lateral (MEV); 24-25 Parapiptadenia zehntneri, 24 - vista lateral (MO), 25 - vista frontal (MEV); 26-27 Pithecelobium diversifolium, 26 - vista frontal, superfície (MO), 27 - vista lateral (MEV); 28-30 Senegalia piauhiensis, 28 - vista frontal, superfície (MO), 29 - vista frontal (MEV), 30 - vista lateral (MEV). Escalas: $10 \mu \mathrm{m}$.

1. Mônades

2. Grãos de pólen de tamanho médio $(\geq 25 \mu \mathrm{m} \leq 50 \mu \mathrm{m})$

D. pernambucanus

2'. Grãos de pólen de tamanho grande (>50 $\mu \mathrm{m})$. N. plena

1. Tétrades 3

3. Tétrades pequenas ou muito pequenas $(<25 \mu \mathrm{m})$. 4 4. Tétrades tetraédricas, muito pequenas 
4'. Tétrades decussadas romboidais ou tetragonais, pequenas. M. invisa e M. tenuiflora

3. Tétrades médias $(\geq 25 \mu \mathrm{m} \leq 50 \mu \mathrm{m})$. M. quadrivalvis var. leptocarpa

1. Políades 5

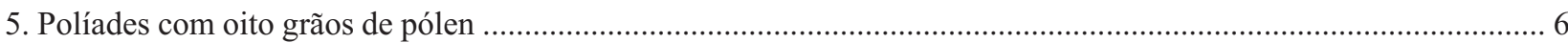

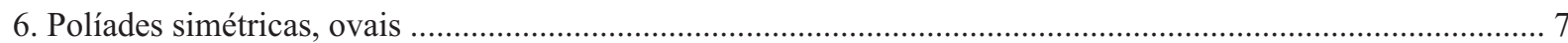

7. Políades organizadas em duas tétrades tetragonais ................................... arenosa e M. ophtalmocentra

7. Políades organizadas em seis grãos periféricos e dois centrais ......................................... Pt. moniliformis

6. Políades plano-elípticas, em forma de gota .................................................................... Ca. depauperata

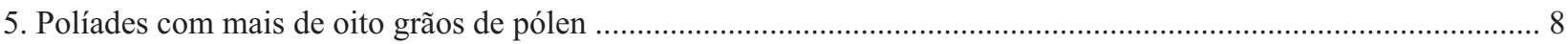

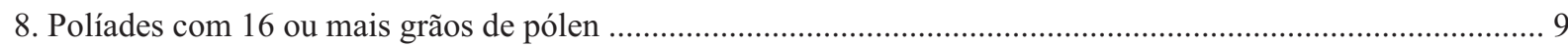

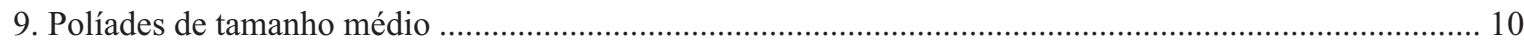

10. Exina areolada

A. colubrina var. colubrina e Pa. zehntneri

10'. Exina psilada

I. vera, e $S$. piauhiensis

9. Políades de tamanho grande .... 11

11. Grãos de pólen com depressões irregulares na superfície distal E. contortisiliqum

11. Grãos de pólen sem depressões irregulares na superfície distal 12

12. Políades com 16 grãos de pólen P. diversifolium

12. Políades com 32 grãos de pólen Ch. dumosum e Ch. foliolosum

8. Políades com 12 grãos de pólen Pp. stipulacea

\section{Discussão}

A heterogeneidade da morfologia polínica indicada por autores anteriores (Van Campo \& Guinet 1961; Guinet 1969; 1981; Sorsa 1969) para a subfamília Mimosoideae foi corroborada com a análise dos táxons ocorrentes na área de estudo. A característica mais marcante é a ocorrência de diferentes tipos de unidades de dispersão, que, de acordo com Sorsa (1969), é a principal característica para a classificação palinológica desta subfamília

Em um trabalho que não utilizou métodos cladísticos, Sorsa (1969) sugeriu que as mônades encontradas em Mimosoideae representam o tipo plesiomórfico e as políades com 16 grãos de pólen ou mais, o tipo apomórfico, havendo derivações mais basais no caso das políades com grãos de pólen heteromórficos (presentes em Calliandra) ou mais apomórficas, como no caso das tétrades (presentes em Mimo$s a$ ). Com relação às mônades, presentes nesta subfamília em gêneros como Leucaena, Prosopis, Desmanthus, Neptunia e Pentaclethra (Guinet 1969; 1981; Sorsa 1969), estariam mais relacionadas às Caesalpinioideae, que também têm grãos de pólen em mônades tricolpadas (Sorsa 1969). Comparando às análises filogenéticas da família, a hipótese lançada por Sorsa (1969) baseada apenas na morfologia polínica corrobora o posicionamento basal de Neptunia e Desmanthus e o derivado de Inga e Chloroleucon (Wojciechowski 2004).

$\mathrm{O}$ gênero Neptunia foi originalmente descrito por De Candolle como uma seção de Desmanthus, mas em seguida não apenas foi aceito como gênero distinto, como ambos foram posicionados em tribos diferentes (Windler 1966). Como visto neste trabalho e anteriormente já citado por Sorsa (1969), os caracteres polínicos não são informativos para a segregação desses gêneros, pois como nas análises aqui apresentadas, ambos os gêneros têm grãos de pólen 3-colporados e estriados. Além da afinidade palinológica, macromorfologicamente, as duas espécies destacaram-se entre as Mimosoideae da flora de Mirandiba por serem as únicas a apresentarem glomérulos heteromórficos como tipo de inflorescência (Córdula et al. 2008).

A espécie Calliandra depauperata também se destacou das demais pelas políades em forma de gota e com um grão apical diferenciado. Essa espécie foi estudada por Santos \& Romão (2008), que descreveram a morfologia polínica 21 espécies de Calliandra ocorrentes na Bahia. Esses autores organizaram as espécies estudadas em dois grupos: a) espécies com políade na qual o grão apical tem um longo apêndice e b) espécies onde o grão apical sem apêndice tem um poro na extremidade. Nesse último tipo, os autores incluíram $C$. depauperata, o que também está corroborado com os dados aqui apresentados.

As políades com 16 grãos de pólen organizadas em 8 $(4+4)$ centrais e 8 periféricos são comumente referidas para as tribos Acacieae, no gênero Acacia (Silvestre-Capelato \& Melhem 1997; Du Bocage et al. 2008) e para a tribo Ingeae, incluindo os gêneros Inga e Pithecellobium (Silvestre-Capelato \& Melhem 1997; Caccavari \& Dome 2000). Segundo Barros (1963), as mônades que compõem as políades desses grupos se caracterizam por serem homogêneas quanto ao número de aberturas, não havendo diferença na quantidade de poros presentes nas mônades do centro e da periferia das políades, ao contrário de Chloroleucon, por exemplo.

Sorsa (1969) posicionou Anadenanthera, tribo Mimosae, em um grupo polínico distinto do de Inga e Pithecellobium, apesar da grande semelhança principalmente da organização 
31

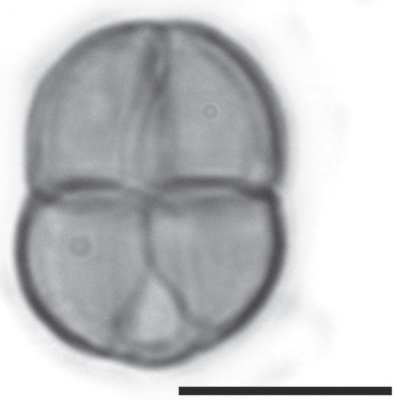

34

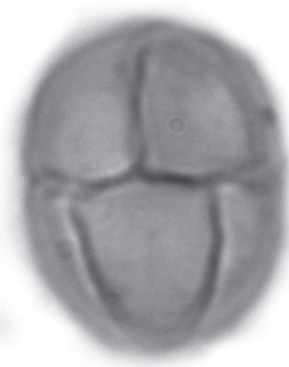

37

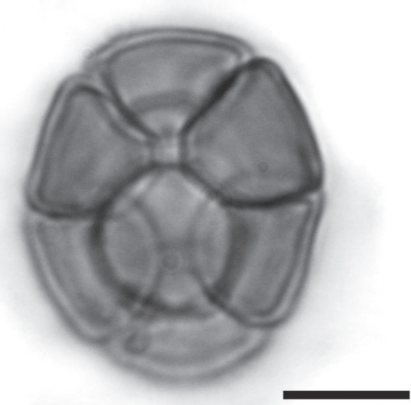

40

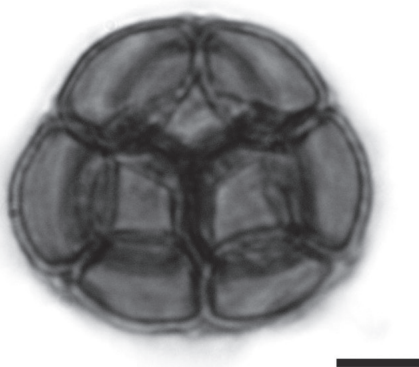

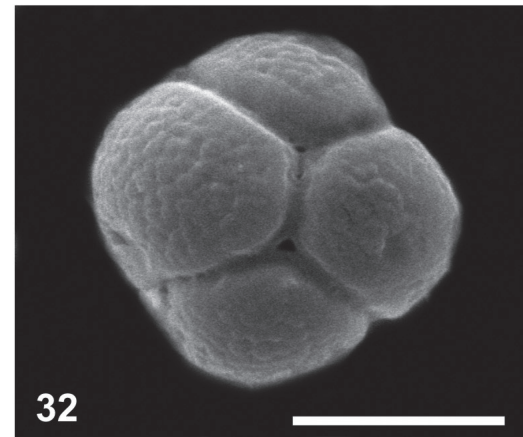
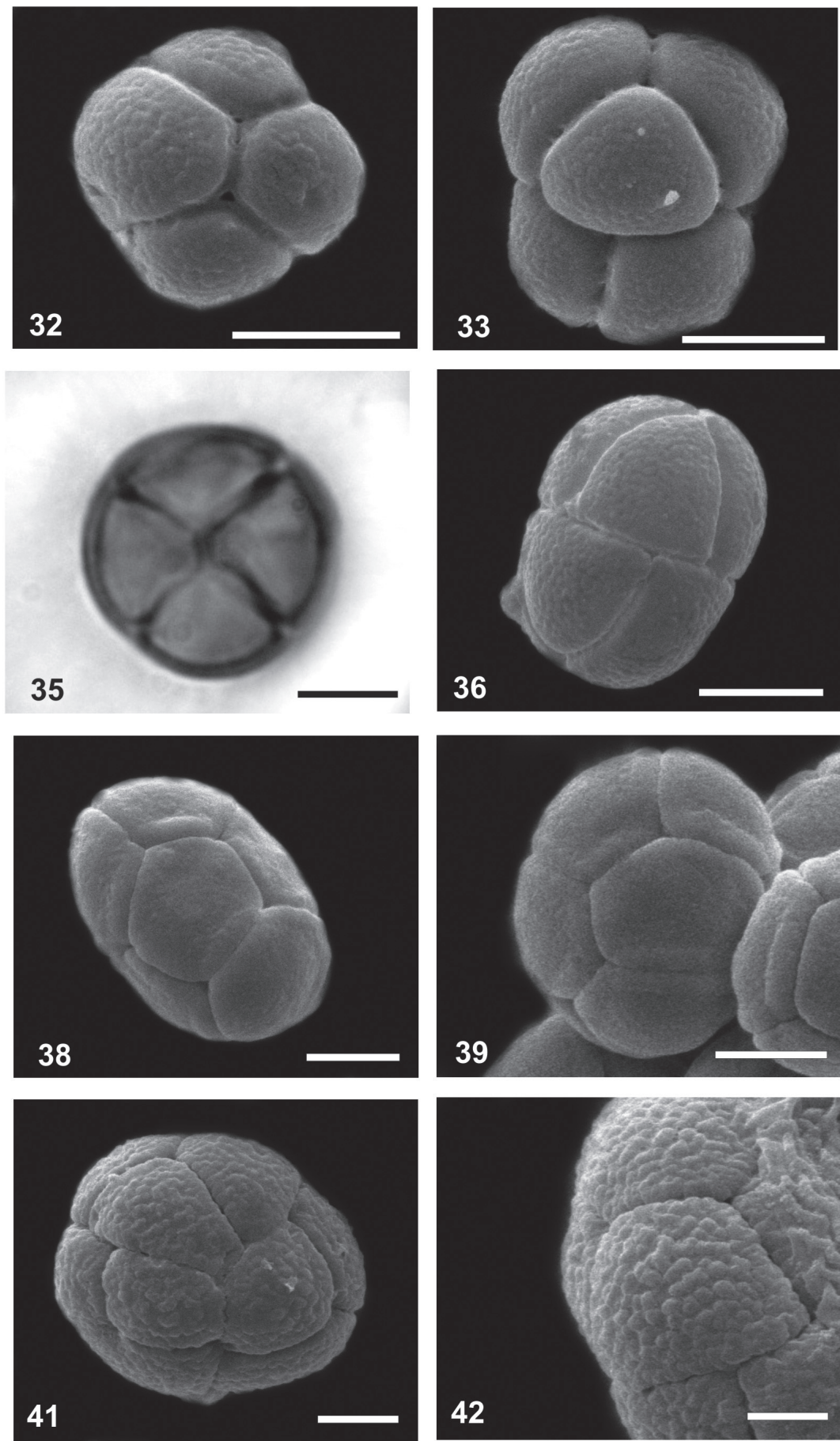

Figuras 31-42. Grãos de pólen de Leguminosae Mimosoideae de Mirandiba, Pernambuco, Brasil. - Tipos 4 e $5.31-33$ Mimosa arenosa, 31 - corte óptico (MO), 32-33 - vista geral (MEV); 34-36 Mimosa ophtalmocentra, 34 - superfície (MO), 35- corte óptico (MO), 36 - vista geral (MEV); $37-39$ Pityrocarpa moniliformis, 37 - corte óptico (MO), 38 - vista geral (MEV), 39 - superfície (MEV); 40-42 Piptadenia stipulacea, 40 - corte óptico, detalhe (MO), 41 - vista lateral (MEV), 42 - vista geral (MEV). Escalas: $5 \mu \mathrm{m}$.

das políades nesses gêneros. Contudo, no presente trabalho, A. colubrina foi agrupada a esses gêneros, embora não sejam relacionados taxonomicamente. O caráter polínico mais marcante para a distinção dessa espécie das demais encontradas em Mirandiba é a presença de aréolas de forma e tamanhos irregulares. Essa caracterização palinológica corrobora a descrição realizada por Silvestre-Capelato \& Melhem (1997).
A relação entre os táxons de Mimosa e Piptadenia, incluindo Pityrocarpa recentemente segregado de Piptadenia (Jobson \& Luckow 2007), já foi citada por Caccavari (1987) ao registrar políades com 8-12 células em Mimosa ser. Glanduliferae Benth.. O gênero Mimosa é reconhecidamente heterogêneo palinologicamente (Caccavari 1985; 1986; Lima et al. 2008), podendo os caracteres polínicos ser 
43
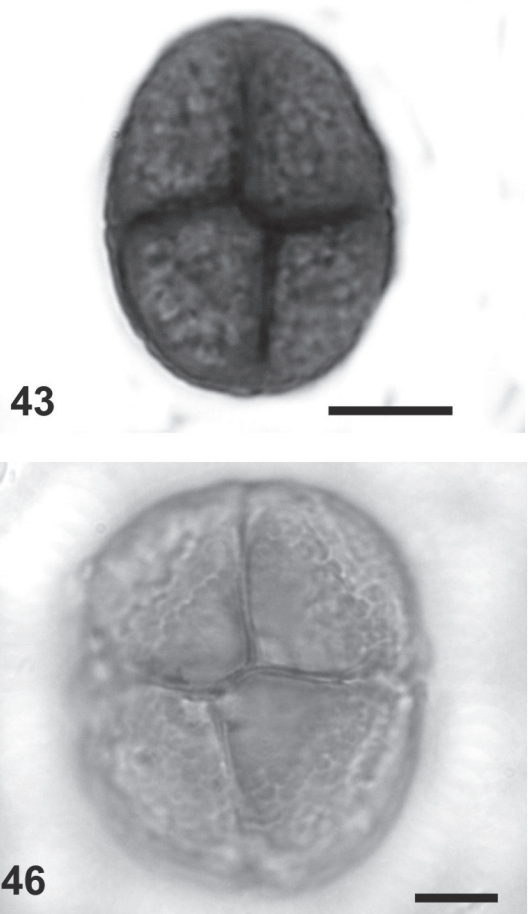

49
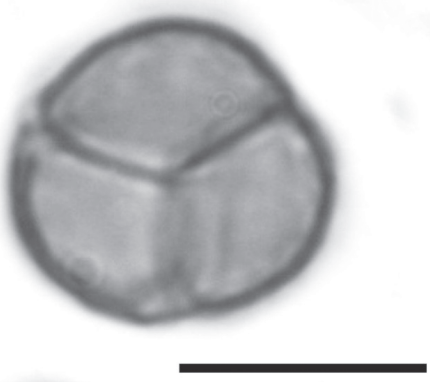

52

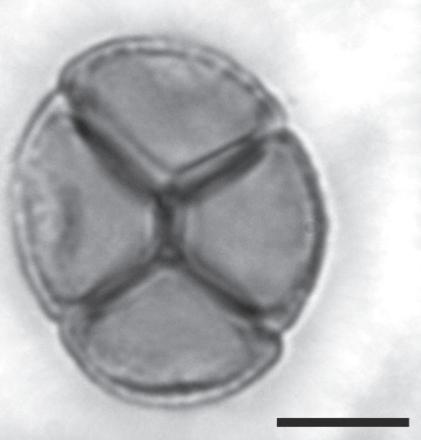

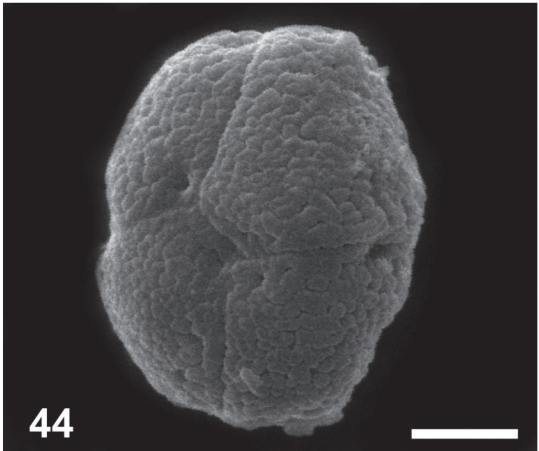
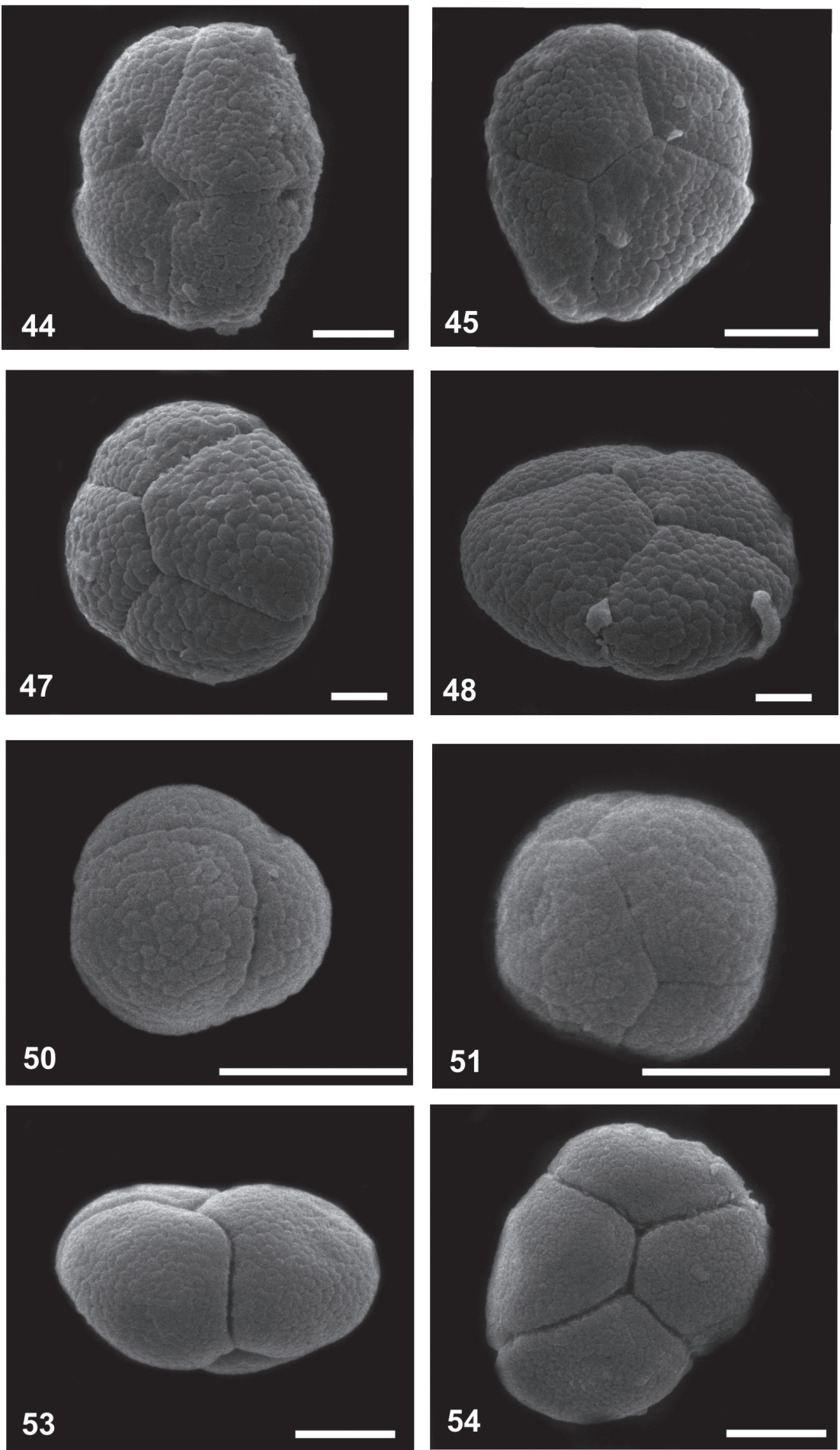

Figuras 43-54. Grãos de pólen de Leguminosae Mimosoideae de Mirandiba, Pernambuco, Brasil. - Tipo 6. 43-45 Mimosa invisa, 43 - corte óptico (MO), 44-45 - vista geral (MEV); 46-48 Mimosa quadrivalvis var. leptocarpa, 46 - superfície (MO), 47 - vista frontal (MEV), 48 - vista lateral (MEV); $49-51$ Mimosa sensitiva, 49 corte óptico (MO), 50 e 51 - vista geral (MEV); 52-54 Mimosa tenuiflora, 52 - corte óptico (MO), 53 - vista lateral (MEV), 54 - vista frontal (MEV). Escalas: 5 um.

de utilidade na separação de suas seções e séries. Da mesma forma, Piptadenia também é considerado euripolínico e com grupos facilmente distintos a partir da morfologia polínica (Caccavari 1987; 2002).

Além da estrutura das unidades polínicas, Sorsa (1969) ressalta que os caracteres de estrutura de parede e forma das aberturas também são relevantes para a palinotaxonomia de Mimosoideae. Recentemente, Santos \& Romão (2008) corroboraram Sorsa (1969) ao indicarem diferenças na superfície da ectexina e na estrutura da exina para diferentes grupos de espécies de Calliandra. Niezgoda et al. (1983), ao estudarem a ultraestrutura da parede de algumas 

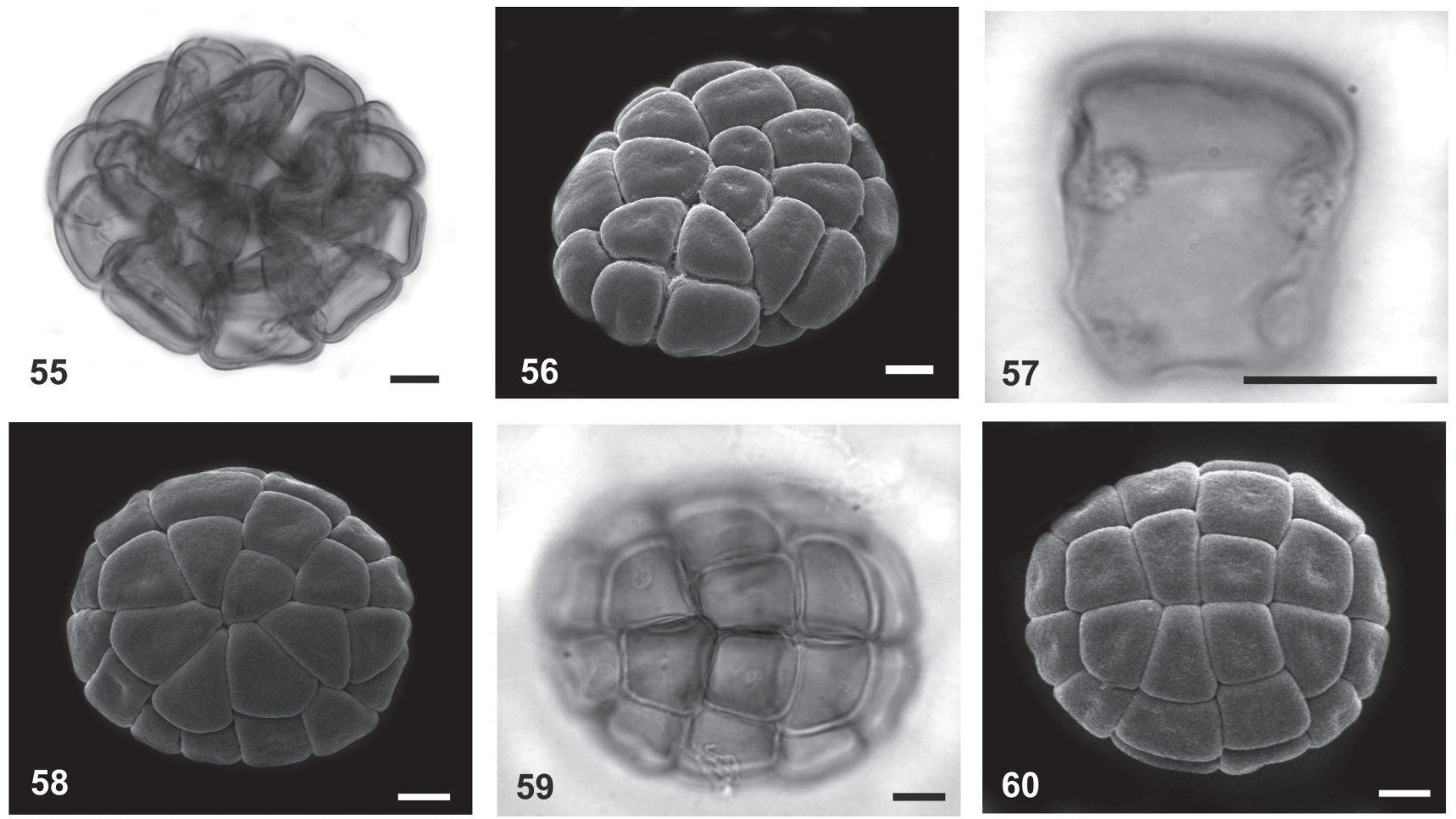

Figuras 55-60. Grãos de pólen de Leguminosae Mimosoideae de Mirandiba, Pernambuco, Brasil. - Tipo 7. 55-56 Chloroleucon dumosum, 55 -corte óptico (MO), 56 - vista geral (MEV); 57-58 Chloroleucon foliolosum, 57 - detalhe de um grão isolado da políade (MO), 58 - vista geral (MEV); 59-60 Enterolobium contortisiliqum, 59 - superfície (MO), 60 - vista geral (MEV). Escalas: $10 \mu \mathrm{m}$.

Tabela 1. Morfometria das unidades polínicas de espécies de Mimosoideae (Leguminosae) ocorrentes em Mirandiba, PE. DM = diâmetro maior; Dm= diâmetro menor; exina, sexina e nexina; em $\mu \mathrm{m}$. M = mônade; P8m = políade multiplanar com oito grãos de pólen; P8u = políade uniplanar com oito grãos de pólen; P12 = políade com doze grãos de pólen; P16 = políade com dezesseis grãos de pólen; P32 = políade com trinta e dois grãos de pólen; T = tétrade .

\begin{tabular}{|c|c|c|c|c|c|}
\hline Espécies [unidade polínica]/Espécimes & $\mathrm{DM}^{\mathrm{a}}$ & $\mathrm{Dm}^{\mathrm{a}}$ & Exina & Sexina & Nexina \\
\hline \multicolumn{6}{|l|}{ Anadenanthera colubrina (Vell.) Brenan var. colubrina [P16] } \\
\hline E. Córdula 195 & $(33,3) 36,2(40,4)$ & $(30,9) 33,3(35,7)$ & 2,5 & 1,5 & 1,0 \\
\hline W. Ganev 2666 & $(35,0) 38,2(41,2)$ & $(31,2) 34,5(37,5)$ & 2,5 & 1,5 & 1,0 \\
\hline W. Ganev 2668 & $(31,2) 39,1(43,7)$ & $(34,5) 35,5(38,7)$ & 2,5 & 1,5 & 1,0 \\
\hline \multicolumn{6}{|l|}{ Calliandra depauperata Benth. [P8u] } \\
\hline T.S. Nunes 671 & (120) $127,3(136,3)$ & $(65,3) 68,8(72,0)$ & 7,2 & 4,8 & 2,4 \\
\hline \multicolumn{6}{|l|}{ Chloroleucon dumosum (Benth.) G.P. Lewis [P32] } \\
\hline E. Córdula 210 & $(67,2) 72,0(76,8)$ & $(58,6) 66,1(76,8)$ & 1,9 & - & - \\
\hline L.W. Lima-Verde 352 & $(67,2) 74,7(76,8)$ & $(58,6) 67,2(76,8)$ & 1,9 & - & - \\
\hline L.P. de Queiroz 9803 & $(69,1) 76,8(79,8)$ & $(64,3) 75,8(78,7)$ & 1,9 & - & - \\
\hline \multicolumn{6}{|l|}{ Chloroleucon foliolosum (Benth.) G.P. Lewis [P32] } \\
\hline R.F. Vieira \& G.P. Silva. s.n. (HUEFS 48939) & $(72,0) 77,8(85,5)$ & $(67,2) 71,7(76,8)$ & 2,0 & 1,0 & 1,0 \\
\hline C.M.L. Aguiar 07 & $(71,1) 76,8(85,5)$ & $(67,2) 71,1(74,9)$ & 2,0 & 1,0 & 1,0 \\
\hline \multicolumn{6}{|l|}{ Desmanthus pernambucanus (L.) Thell. [M] } \\
\hline E. Córdula 239 & $(35,0) 39,2(45,0)^{\mathrm{b}}$ & $(40,0) 44,4(47,5)^{\mathrm{c}}$ & 2,5 & 1,5 & 1,0 \\
\hline E. Córdula 56 & $(35,7) 37,0(40,5)^{\mathrm{b}}$ & $(40,5) 44,4(47,6)^{\mathrm{c}}$ & 2,1 & 1,1 & 1,0 \\
\hline L.P. de Queiroz 9038 & $(32,5) 35,0(37,5)^{\mathrm{b}}$ & $(38,7) 44,5(50,0)^{\mathrm{c}}$ & 2,5 & 1,5 & 1,0 \\
\hline \multicolumn{6}{|l|}{ Enterolobium contortisiliquum (Vell.) Morong [P32] } \\
\hline B.M.T. Walter 3830 & $(75,8) 80,4(97,9)$ & $(62,4) 75,2(85,4)$ & 2,0 & 1,0 & 1,0 \\
\hline N. Roque s.n. (HUEFS 28730) & $(76,8) 84,1(91,2)$ & $(72,0) 75,8(78,7)$ & 2,0 & 1,0 & 1,0 \\
\hline
\end{tabular}


62 Buril et al.: Diversidade polínica das Mimosoideae (Leguminosae) ocorrentes em uma área de caatinga, Pernambuco, Brasil

Tabela 1. Continuação

\begin{tabular}{|c|c|c|c|c|c|}
\hline Espécies [unidade polínica]/Espécimes & $\mathrm{DM}^{\mathrm{a}}$ & $\mathrm{Dm}^{\mathrm{a}}$ & Exina & Sexina & Nexina \\
\hline \multicolumn{6}{|l|}{ Inga vera Willd. [P16] } \\
\hline E. Córdula 263 & $(31,2) 35,8(41,4)$ & $(31,2) 31,5(36,1)$ & 2,5 & 1,5 & 1,0 \\
\hline \multicolumn{6}{|l|}{ Mimosa arenosa (Willd) Poir. [P8m] } \\
\hline E. Córdula 301 & $(12,5) 13,7(14,4)$ & $(9,6) 10,1(10,6)$ & $<1$ & - & - \\
\hline J.S. Silva 196 & $(12,5) 13,9(15,4)$ & $(9,6) 10,1(11,5)$ & $<1$ & - & - \\
\hline Y. Melo 186 & $(12,5) 13,7(15,4)$ & $(8,7) 9,8(10,6)$ & $<1$ & - & - \\
\hline \multicolumn{6}{|l|}{ Mimosa invisa Mart. ex Colla [T] } \\
\hline E. Córdula 83 & $(22,1) 23,4(25,9)$ & $(16,3) 18,4(20,2)$ & 1,1 & - & - \\
\hline E. Córdula 272 & $(22,1) 23,6(25,0)$ & $(16,3) 17,9(19,2)$ & 1,4 & - & - \\
\hline \multicolumn{6}{|l|}{ Mimosa ophthalmocentra Mart. ex Benth. [P8m] } \\
\hline L.C.L. Lima 180 & $(13,4) 14,2(14,4)$ & $(9,6) 10,1(10,6)$ & $<1$ & - & - \\
\hline M.F. Simon 701 & $(13,4) 13,6(14,4)$ & $(9,6) 9,8(10,6)$ & $<1$ & - & - \\
\hline L.P. de Queiroz 9521 & $(12,5) 13,1(13,4)$ & $(8,6) 9,6(10,6)$ & $<1$ & - & - \\
\hline \multicolumn{6}{|l|}{ Mimosa quadrivalvis var. leptocarpa (DC.) Barneby [T] } \\
\hline D.A.Araújo 207 & $(33,3) 37,4(40,5)$ & $(23,8) 28,9(31,0)$ & 1,2 & 0,6 & 0,6 \\
\hline E. Córdula 30 & $(33,6) 36,2(38,4)$ & $(27,8) 30,1(30,7)$ & 1,2 & 0,6 & 0,6 \\
\hline E. Córdula 275 & $(35,5) 36,9(40,3)$ & $(27,8) 31,0(35,5)$ & 1,0 & 0,5 & 0,5 \\
\hline \multicolumn{6}{|l|}{ Mimosa sensitiva L. [T] } \\
\hline Y. Melo 182 & $(7,7) 8,8(9,6)$ & - & $<1$ & - & - \\
\hline E. Córdula 266 & $(7,7) 8,5(9,6)$ & - & $<1$ & - & - \\
\hline E. Córdula 11 & $(7,7) 8,9(9,6)$ & - & $<1$ & - & - \\
\hline \multicolumn{6}{|l|}{ Mimosa tenuiflora (Willd.) Poir. [T] } \\
\hline M.T. Vital 87 & $(16,6) 21,2(23,8)$ & $(14,3) 15,7(19,0)$ & 1,0 & - & - \\
\hline E. Córdula 186 & $(18,2) 20,7(24,0)$ & $(13,4) 14,7(13,3)$ & 1,0 & - & - \\
\hline L.P. de Queiroz 7874 & $(18,2) 21,4(23,8)$ & $(14,3) 15,2(13,3)$ & 1,0 & - & - \\
\hline \multicolumn{6}{|l|}{ Neptunia plena (L.) Benth. [M] } \\
\hline E. Córdula 288 & $(50,0) 56,2(71,4)^{b}$ & $(54,7) 61,6(71,4)^{\mathrm{c}}$ & 5,3 & 3,6 & 1,7 \\
\hline Y. Melo 161 & $(59,5) 61,7(66,7)^{\mathrm{b}}$ & $(61,8) 68,1(73,8)^{\mathrm{c}}$ & 5,6 & 3,6 & 2,0 \\
\hline L.P. de Queiroz 4831 & $(52,4) 57,4(59,5)^{\mathrm{b}}$ & $(64,3) 69,2(73,8)^{\mathrm{c}}$ & 5,1 & 3,6 & 1,5 \\
\hline \multicolumn{6}{|l|}{$\begin{array}{l}\text { Parapiptadenia zehntneri (Harms) M.P.M. } \\
\text { de Lima \& H.C. de Lima [P16] }\end{array}$} \\
\hline J.R.Lemos 262 & $(23,8) 28,5(30,9)$ & - & 1,1 & - & - \\
\hline G.P. Silva s.n. (HUEFS 72632) & $(26,2) 31,1(35,7)$ & - & 1,3 & - & - \\
\hline G.P. Silva s.n. (HUEFS 11729) & $(23,8) 27,2(33,3)$ & - & 1,1 & - & - \\
\hline \multicolumn{6}{|l|}{ Piptadenia stipulacea (Benth.) Ducke [P12] } \\
\hline J.S.Silva 166 & $(21,2) 23,2(25,0)$ & $(17,5) 19,5(21,2)$ & 1,0 & - & - \\
\hline E. Córdula 261 & $(22,5) 24,2(27,5)$ & $(17,5) 19,4(21,2)$ & 1,0 & - & - \\
\hline Y. Melo 183 & $(23,8) 26,0(30,0)$ & $(17,5) 19,2(21,2)$ & 1,0 & - & - \\
\hline \multicolumn{6}{|l|}{ Pithecelobium diversifolium Benth. [P16] } \\
\hline E. Córdula 208 & $(76,2) 79,9(83,3)$ & $(69,0) 71,4(73,8)$ & 2,0 & 1,0 & 1,0 \\
\hline L.P. de Queiroz 9903 & $(71,4) 75,5(83,3)$ & - & 2,0 & 1,0 & 1,0 \\
\hline A.M. Carvalho 3877 & $(66,7) 73,2(76,2)$ & - & 2,0 & 1,0 & 1,0 \\
\hline \multicolumn{6}{|c|}{ Pityrocarpa moniliformis (Benth.) Luckow \& R.W.Jobson [P8m] } \\
\hline M.T. Vital 72 & $(18,2) 19,7(21,1)$ & $(13,4) 14,7(15,4)$ & 1,0 & - & - \\
\hline E. Córdula 24 & $(17,3) 18,7(21,1)$ & $(13,4) 14,1(15,4)$ & 1,0 & - & - \\
\hline L.L. Silva 219 & $(18,2) 20,4(22,1)$ & $(13,4) 14,8(15,4)$ & 1,0 & - & - \\
\hline
\end{tabular}


Tabela 1. Continuação

\begin{tabular}{|c|c|c|c|c|c|}
\hline Espécies [unidade polínica]/Espécimes & $\mathrm{DM}^{\mathrm{a}}$ & $\mathrm{Dm}^{\mathrm{a}}$ & Exina & Sexina & Nexina \\
\hline \multicolumn{6}{|l|}{ Senegalia piauhiensis (Benth.) Seigler \& Ebinger [P16] } \\
\hline E. Córdula 43 & $(40,0) 43,2(46,0)$ & $(36,0) 40,7(45,0)$ & 1,8 & 0,9 & 0,9 \\
\hline E. Córdula 212 & $(35,7) 38,2(42,8)$ & - & 2,0 & 1,0 & 1,0 \\
\hline
\end{tabular}

a Média (faixa de variação); ${ }^{\text {b }}$ Diâmetro polar; c Diâmetro equatorial.

Mimosoideae, consideraram as políades de Enterolobium contortisiliquum, espécie aqui estudada também, como parcialmente calimadas com a ectexina contínua ao redor dos grãos de pólen, característica essa considerada como derivada por Guinet (1969).

Em Mirandiba, as espécies de Chloroleucon e Enterolobium podem ser agrupadas pela presença de políades com mais de 16 grãos de pólen. Esse último gênero foi estudado por Sorsa (1969) que o incluiu no grupo considerado como mais derivado na subfamília. Em ambos os gêneros, são encontradas políades com 16 a 32 grãos de pólen, característica comum a outros gêneros da tribo Ingeae (Niezgoda et al. 1983; Caccavari \& Dome 2000).

Diante dos resultados, as espécies de Mimosoideae ocorrentes em Mirandiba são amplamente diversas palinologicamente, retratando toda a variedade de formas já tão bem explorada na subfamília, e os tipos estabelecidos auxiliam no fácil reconhecimento das espécies que ocorrem na área de estudo.

\section{Agradecimentos}

À Msc. Elisabeth Córdula e ao Prof. Dr. Luciano Paganucci de Queiroz pela identificação das espécies; à MSc. Gisele P. Rocha pela obtenção das eletromicrografias; à CAPES pela concessão da Bolsa de Mestrado da primeira autora; ao CNPq pela concessão de Bolsa de Produtividade Científica ao segundo autor; à Fundação O Boticário pelo financiamento do Projeto Flora de Mirandiba.

\section{Referências bibliográficas}

Barros, M.M. 1963. Contribuição ao estudo das políades polínicas em Leguminosae-Mimosoideae. Atas da Sociedade de Biologia do Rio de Janeiro 7: 1-11.

Du Bocage, A.L.; Souza, M.A.; Miotto, T.S. \& Gonçalves-Esteves, V. 2008. Palinotaxonomia de espécies de Acacia (Leguminosae - Mimosoideae) no semi-árido brasileiro. Rodriguésia 59(3): 587-596.

Caccavari, M.A. 1985. Granos de pólen de leguminosas de la Argentina. IV - Gênero Mimosa. Boletín de la Sociedad Argentina de Botánica 24: $151-167$.

Caccavari, M.A. 1986. Estudio de los caracteres del polen en las Mimosa - Lepidotae. Pollen et Spores 18: 29-42.

Caccavari, M.A. 1987. Estudio de los granos de polen en las MimosaGlanduliferae. Actas del VII Simposio Argentino de Paleobotánica y Palinología, Buenos Aires: 141-145.

Caccavari, M.A. 2002. Pollen morphology and structure of Tropical and Subtropical American genera of the Piptadenia-group (Leguminosae: Mimosoideae). Grana 41: 130-141.

Caccavari, M.A. \& Dome, E. 2000. An account of morphological and structural characterization of American Mimosoideae pollen. Part I: Tribe Acacieae. Palynology 24: 231-248.

Van Campo, M. \& Guinet, P. 1961. Les pollens composes. L'exemple des Mimosacees. Pollen et Spores 3: 201-218.
Córdula, E.; Queiroz, L.P. \& Alves, M. 2008. Checklist da flora de Mirandiba, Pernambuco: Leguminosae. Rodriguésia 59: 597-602.

Erdtman, G. 1960. The acetolysis method. A revised description. Svensk Botanisk Tidskrift 39: 561-564.

Giulietti, A.M.; Harley, R.M.; Queiroz, L.P.; Barbosa, M.R.V.; Bocage, A.L. \& Figueiredo, M.A. 2002. Espécies endêmicas da Caatinga. In: Sampaio, E.V.S.B.; Giulietti, A.M.; Virgínio, J. \& Gamarra-Rojas, C.F.L. (Eds.) Vegetação e Flora da Caatinga. Recife, Associação Plantas do Nordeste.

Guinet, Ph. 1969. Lês Mimosacées - Étude de palynologie fondamentale corrélations, évolution. Travaux de la Section Scientifique et Technique 9: 32-261.

Guinet, Ph. 1981. Comparative account of pollen characters in the Leguminosae. Pp. 789-799.In: Polhill, R.M. \& Raven, P.H. (ed.). Advances in Legume Systematics - part 2. Kew, Royal Botanic Gardens.

Holmgren, P.K. \& Holmgren, N.H. 2006. Index Herbariorum. New York Botanical Garden. Disponível em: http://sciweb.nybg.org/science2/ IndexHerbariorum.asp (Acesso em: 15 jul. 2008).

Jobson, R.W. \& Luckow, M. 2007. Phylogenetic study of the genus Piptadenia (Mimosoideae: Leguminosae) using plastid trnL-F and trnK/matK sequence data. Systematic Botany 32: 569-575.

Judd, W.S.; Campbell, C.S.; Kellogg, E.A. \& Stevens, P.F. 1999. Plant Systematics, a Phylogenetic Approach. Suderland, Sinauer Associates, Inc.

Kunth, K.S. 1819 [-1824]. Mimoses et autres plantes légumineuses du Nouveau Continent. Recueillies par MM. de Humboldt et Bonpland, décrites et publiées par Charles Sigismund Kunth. vol. 2.

Lewis, G.P. 1987. Legumes of Bahia. Kew, Royal Botanic Gardens.

Lima, L.C.L.; Silva, F.H.M. \& Santos, F.A.R. 2008. Palinologia de espécies de Mimosa L. (Leguminosae - Mimosoideae) do Semi-Árido brasileiro. Acta Botanica Brasilica 22: 794-805.

Melhem, T.S.A.; Cruz-Barros, M.A.V.; Corrêa, A.M.S.; Makino-Watanabe, H.; Silvestre-Capelato, M.S.F. \& Esteves, V.L.G. 2003. Variabilidade polínica em plantas de Campos do Jordão (São Paulo, Brasil). Boletim do Instituto de Botânica 16: 1-104.

Ministério do Meio Ambiente - MMA/SBF. 2002. Avaliação e Ações Prioritárias para a conservação da Biodiversidade da Caatinga. Brasilia, UFPE/FADE/Conservation Internacional do Brasil/Fundação Biodiversitas/Semi-Árido.

Von Mohl H. 1835. Sur la structure et lês formes des grains de pollen. Annales des Sciences Naturelles - Botanique 2: 148-181.

Niezgoda, C.J.; Feuer, S.M. \&Nevling, L.I. 1983. Pollen ultraestructure of the tribe Ingeae (Mimosoideae: Leguminosae). American Journal of Botany 70: 650-667.

Punt, W.; Hoen, P.P.; Blackmore, S.; Nilsson, S. \& Le Thomas, A. 2007. Glossary of pollen and spores terminology. Review of Paleobotany and Palynology 143: 1-81.

Queiroz, L.P. 2006. The Brazilian Caatinga: Phytogeographical Patterns Inferred From Distribution Data of the Leguminosae. Pp. 113-149. In: Pennington, R.T.; Lewis, G.P. \& Ratter, J.A. (Eds.). Neotropical savannas and dry forests: plant diversity, biogeography, and conservation. Boca Raton, Taylor \& Francis CRC-Press.

Rosanoff, S. 1865. Zur Kenntniss des Baues und der Entwicklungsgeschichte des Pollens der Mimoseae. Jahrbücher für wissenschaftliche Botanik 4: 441-450.

Sampaio, E.V.S.B. 1995. Overview of the Brazilian Caatinga. In: Bullock, S.H.; Mooney, H. A. \& Medina, E. (Eds.). Seasonally dry tropical forests. Cambridge, Cambridge University Press. 
64 Buril et al.: Diversidade polínica das Mimosoideae (Leguminosae) ocorrentes em uma área de caatinga, Pernambuco, Brasil

Sampaio, E.V.S.B; Giulietti, A.M.; Virgínio, J. \& Gamarra-Rojas, C. (orgs.). 2002. Vegetação e Flora da Caatinga. Associação de Plantas do Nordeste (APNE) e Centro Nordestino de Informações sobre Plantas (CNIP), Recife.

Santos, F.A.R. \& Romão, C.O. 2008. Pollen morphology of some species of Calliandra Benth. (Leguminosae - Mimosoideae) from Bahia, Brazil. Grana 47: 101-116.

Silvestre-Capelato, M.S.F. \& Melhem, T.S. 1997. Flora polínica da reserva do Parque Estadual das Fontes do Ipiranga (São Paulo, Brasil) família: Leguminosae. Hoehnea 24: 115-163.

Simpson, M.G. 2006. Plant Systematics. Amsterdam, Elsevier-Academic Press.

Smith, N.; Mori, S.A.; Henderson, A.; Stevenson, D.W. \& Heald, S.V. 2004 Flowering Plants of the Neotropics. New York, New York Botanical Garden, Princeton University Press. p. 151-156.
Sorsa, P. 1969. Pollen morphological studies on the Mimosaceae. Annales Botanici Fennici 6: 1-34.

Souza, V.C. \& Lorenzi, H. 2005. Botânica Sistemática: Guia ilustrado para identificação das famílias de Angiospermas da flora brasileira, baseado em APG II. Nova Odessa, Instituto Plantarum. p. 291-328.

Vishnu-Mitre \& Sharma, B.D. 1962. Studies of Indian pollen grains. 1 Leguminosae. Pollen et spores 4: 6-45.

Windler, D.R. 1966. A revision of the genus Neptunia (Leguminosae). Australian Journal of Botany 14: 379-420.

Wojciechowski, M.F.; Lavin, M. \& Sanderson, M.J. 2004. A phylogeny of Legumes (Leguminosae) based on analysis of the plastid MATK gene resolves many well-supported subclades within the family. American Journal of Botany 9: 1846-1862. 